\title{
Zinc Chloride Induced Meiotic Aberrations in Green Manure Crop Sesbania cannabina Poir. (Dhaincha)
}

\author{
Nitisha Srivastava* and Girjesh Kumar \\ Plant Genetics Laboratory, Department of Botany, University of Allahabad, Allahabad-211002, U. P., India
}

Received October 3, 2018; accepted December 8, 2018

\begin{abstract}
Summary Sesbania cannabina commonly known as Dhaincha in India is adaptable to different adverse climatic conditions such as waterlogging, drought, soil salinity etc. and is widely used as green manure crop and may have potential as forage for cattle. Heavy metal toxicity in soil possesses a major threat to plant growth and development. Effect of zinc chloride on germination, survival percentage and meiotic divisions of S. cannabina were studied. For this purpose, the soaked seeds of $S$. cannabina were treated with different concentrations zinc chloride solution i.e., 25, 50, 100 and $200 \mathrm{ppm}$ for $3 \mathrm{~h}$ and sown to rise $\mathrm{M}_{1}$ generation. Seed germination percentage was highest in control as compared to treated sets and it tends to decrease with increasing doses of treatment. Plants grown from treated seeds of all doses showed diversity among themselves regarding survival percentages. The result showed varied chromosomal anomalies, scattering, stickiness, unorientaion, disturbed metaphase, precocious movement, lagging chromosome, bridge formation etc. Meiotic aberrations were also found to be increased with the increase in treatment doses.
\end{abstract}

Key words Chromosomal aberration, Germination percentage, Sesbania cannabina, Survival percentage.

In the present era of industrialization environmental pollution has emerged as a big challenge for human beings. Heavy metal pollution in the soil has created a serious problem, which has received much attention from all over the world. Heavy metals are an important class of environmental hazards and become toxic when they are not metabolized by the body and accumulated in the soft tissues. Heavy metals may enter the human body through food, water, air, or absorption through the skin when they come in contact with humans in agriculture and in manufacturing, pharmaceutical, industrial, or residential settings. Zinc is an essential nutrient for living organisms, representing the 23rd most abundant element on earth (Broadley et al. 2007) and the 2nd most abundant transition metal, after iron (Jain et al. 2010). Accumulation of $\mathrm{Zn}$ in the environment is due to mining and refining of nonferrous metals, chemical industry, burning of fossil fuels, and agricultural utilization of fertilizers and herbicides ( $\mathrm{Zn}$ chloride and $\mathrm{Zn}$ sulfate) (Päivöke 2003a, b). It is a structural stabilizing factor of the cell membrane and DNA-linking proteins (Salama and El Fouly 2008) and it plays a significant role in the control of gene expression and DNA transcription (Päivöke 2003a, b). While the excess quantity of Zn become toxic to plants as they alter physiological processes (Jain et al. 2010).

Phytoremediation technology is gaining great importance in recent time for the removal of elemental pollut-

\footnotetext{
*Corresponding author, e-mail: srivastava_nitisha@yahoo.com DOI: $10.1508 /$ cytologia. 84.127
}

ants from soil and water. There are many plant species which have hyper accumulative capacities but most of them have limitations such as slow growth rate, low biomass production and to remove heavy metals from polluted soil in a timely manner. S. cannabina is a fastgrowing annual leguminous crop and is widely available in many tropical countries of Asia and Africa. Because of its ability to grow in heavy metal soils, withstand waterlogging and tolerate soil salinity, they are often preferred green manure crop (Evans and Rotar 1987). They are able to survive in toxic soil partly due to their inherent tolerance to metal toxicity and partly due to root nodule formation. Among the list of heavy metals zinc has caused widespread environmental contamination during the last 50 years. The objectives of present study were to study the effect of zinc toxicity on germination, survival, and microsporogenesis of green manure crop S. cannabina.

Materials and methods

\section{Zinc chloride treatment and sowing}

Seeds of S. cannabina variety ND-1 obtained from Sunn Hemp Research Station, Pratapgarh, India were soaked in water for $14 \mathrm{~h}$. soaked seeds of S. cannabina were treated with different concentrations of zinc chloride solution i.e., 25, 50, 100 and $200 \mathrm{ppm}$ for $3 \mathrm{~h}$. After treatment, seeds were washed in running water to remove zinc chloride solution and sown to raise the population. Along with the treated seeds, normal seeds were also sown for control set. 


\section{Field studies}

A field study was carried out to determine the effect of zinc chloride on germination and survival percentages. Germination percentages were taken after 15 days of sowing and survival percentages were taken after 30 days of sowing. On the onset of budding the young floral buds were fixed in Carnoy's fixative $(1: 3$, glacial acetic acid: absolute ethanol) in their respective bottles. After $24 \mathrm{~h}$ change the buds in $90 \%$ ethyl alcohol and store in a refrigerator and were used for cytogenetical analysis.

\section{Cytological analysis}

Cytogenetical studies were carried out using $2 \%$ acetocarmine. Slides were prepared using anther squash technique. A detailed microscopic study of pollen grains and pollen mother cells were done for each dose of treatment as well as control.

\section{Results}

\section{Germination and survival percentages}

A comparative account of germination and survival percentages of control and metal treated sets have been tabulated in Table 1. In the control set, seed germination was recorded to be $100 \%$. In zinc metal treatment sets, the value of germination percentages tends to be decreased with increasing dose of treatment. The value of germination and survival percentages at the lowest dose of $25 \mathrm{ppm}$ was $100 \%$, while at the highest dose of $200 \mathrm{ppm}$, germination and survival reduced to $53.33 \%$ and $49.99 \%$, respectively.

\section{Chromosomal aberrations and pollen fertility}

Toxicity of $\mathrm{Zn}$ has been analyzed by assessing the chromosomal aberrations in the PMCs of treated sets as

Table 1. Effect of zinc chloride treatment on germination and survival percentages of S. cannabina.

\begin{tabular}{ccc}
\hline \hline Dose of zinc chloride & Germination $\%$ & Survival \% \\
\hline Control & 100 & 100 \\
$25 \mathrm{ppm}$ & 100 & 100 \\
$50 \mathrm{ppm}$ & 86.66 & 70 \\
$100 \mathrm{ppm}$ & 66.66 & 69.44 \\
$200 \mathrm{ppm}$ & 53.33 & 49.99 \\
\hline
\end{tabular}

these provide an efficient and reliable tool to estimate genetic damage. The metal treatments resulted in a number of meiotic abnormalities spread in all the phases of division in the PMCs (Table 2).

Meiosis was perfectly normal in the control plants showing 12 bivalents at diakinesis, metaphase I (Fig. 1A) and 12:12 separations at anaphase I (Fig. 1B). However, the plants in $\mathrm{Zn}$ treatment set displayed varying degrees of chromosomal abnormalities distributed in all the phases of division. Zinc chloride treatment induced various types of chromosomal aberrations such as unorientation, precocious movement (Fig. 1G), scattering (Fig. 1H) and stickiness (Fig. 1I) at metaphase and unorientation, bridges at anaphase I (Fig. 1D) and laggards at anaphase (Fig. 1C, F). Secondary association (Fig. 1E) was also observed in some PMCs. The values of the total abnormality percentage range from 8.46 to $22.90 \%$ at the doses of $25 \mathrm{ppm}$ and $200 \mathrm{ppm}$, respectively. Metaphasic and anaphasic aberrations showed a dose-dependent increase in abnormality (\%) with increasing concentrations. Unorientation and stickiness at metaphase and Asynchronous and unorientaion at anaphase were the most dominant aberrations in the treated set. Unorientation and bridges at anaphase were found to be totally absent at the lowest dose of treatment of $25 \mathrm{ppm}$.

In the control set, the pollen fertility was recorded to be $94.05 \%$ and in the treated set, the pollen fertility showed a decreasing trend along with increasing doses of treatment (Table 2). In the case of the treated set, the maximum and minimum mean values for pollen fertility percentages were $90.52 \%$ and 78.34 at $25 \mathrm{ppm}$ and $200 \mathrm{ppm}$, respectively.

\section{Discussion}

The cytological study clearly revealed the chromotoxic behavior of Zinc chloride. The pollen mother cells of the treated sets exhibited various types of chromosomal abnormalities during the course of meiosis. Genotoxic behaviors of different toxic metals have been studied by Kiran and Sahin (2006). To evaluate the mutagenicity of heavy metals in plants, the following assays have been proposed: chromosome aberration analysis (Rank and Nielsen 1994), micronucleus tests (Steinkellner

Table 2. Effect of different concentrations of $\mathrm{ZnCl}_{2}$ on total meiotic abnormality (\%) of S. cannabina.

\begin{tabular}{|c|c|c|c|c|c|c|c|c|c|c|c|c|c|c|}
\hline \multirow{2}{*}{$\begin{array}{l}\text { Heavy } \\
\text { metals }\end{array}$} & \multirow{2}{*}{$\begin{array}{l}\text { Doses } \\
(\mathrm{ppm})\end{array}$} & \multirow{2}{*}{$\begin{array}{c}\text { No. of } \\
\text { PMCs } \\
\text { observed }\end{array}$} & \multirow{2}{*}{$\begin{array}{c}\text { No. of } \\
\text { abnormal } \\
\text { PMCs }\end{array}$} & \multicolumn{4}{|c|}{ Metaphasic abnormality (\%) } & \multicolumn{4}{|c|}{ Anaphasic abnormality (\%) } & \multirow{2}{*}{$\begin{array}{c}\text { Others } \\
(\%)\end{array}$} & \multirow{2}{*}{$\begin{array}{c}\text { Total } \\
\text { abnormality } \\
(\%)\end{array}$} & \multirow{2}{*}{$\begin{array}{c}\text { Pollen } \\
\text { fertility } \\
\quad(\%)\end{array}$} \\
\hline & & & & Un & $\mathrm{Sc}$ & $\operatorname{Pr}$ & St & Un & $\mathrm{Br}$ & $\mathrm{Lg}$ & Asy & & & \\
\hline Control & & 290 & - & - & - & - & - & - & - & - & - & - & - & 94.05 \\
\hline \multirow[t]{4}{*}{$\mathrm{ZnSO}_{4}$} & 25 & 185.5 & 15.75 & 0.79 & 1.17 & 1.04 & 0.49 & - & - & 0.96 & 1.34 & 1.64 & 8.46 & 90.52 \\
\hline & 50 & 199.75 & 24.5 & 1.44 & 1.40 & 1.56 & 1.18 & 1.22 & 1.30 & 1.10 & 1.20 & 1.75 & 12.38 & 86.03 \\
\hline & 100 & 165.25 & 26.75 & 2.2 & 1.18 & 1.65 & 2.53 & 1.38 & 1.84 & 1.99 & 1.61 & 1.51 & 16.21 & 80.24 \\
\hline & 200 & 147.27 & 33.75 & 2.88 & 1.55 & 2.42 & 3.06 & 2.28 & 1.42 & 2.22 & 2.29 & 3.75 & 22.90 & 78.34 \\
\hline
\end{tabular}

Un: Unorientation, Sc: scattering, Pr: precocious movement, St: stickiness, Br: bridges, Lg: laggards, Asy: asynchronus, Other abnormalities: Cytomixis, tripolarity, secondary association, multivalents, bivalents etc. 

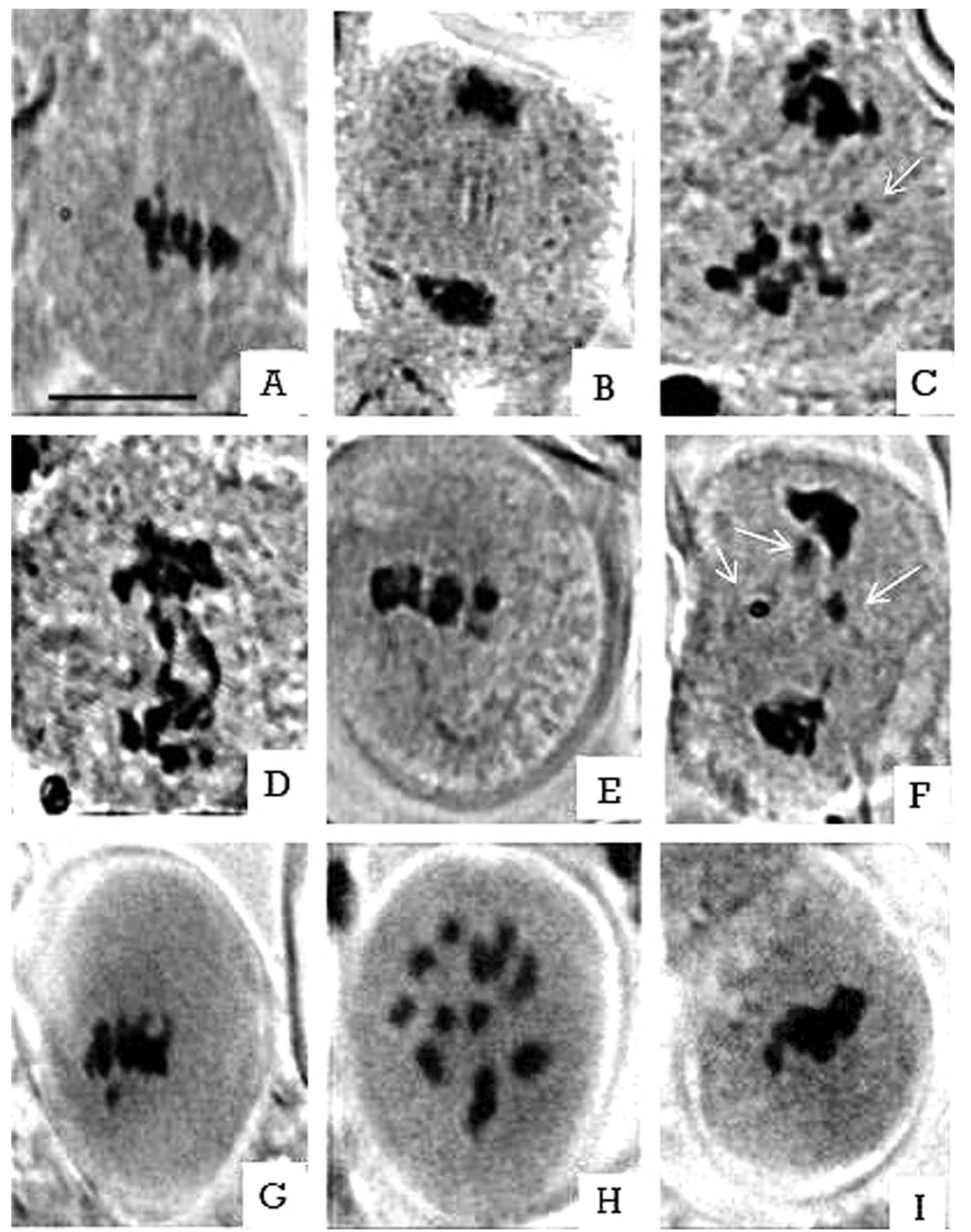

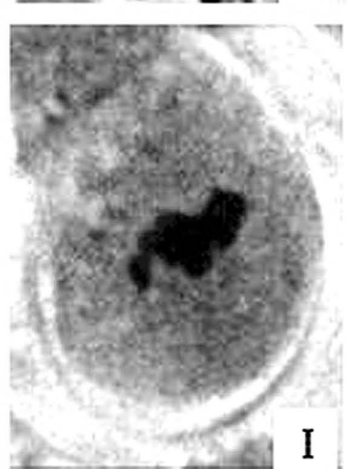

Fig. 1. Different stages and abnormal meiotic divisions in Sesbania Pea: A) PMC in normal metaphase, B) PMC in normal anaphase, C) PMC in anaphase I with one lagging chromosome, D) PMC with bridge formation at anaphase I, F) PMC with multivalents at metaphase I, G) PMC in anaphase I with 3 lagging chromosomes, H) PMC with precocious movement at metaphase I, I) PMC with scattering at metaphase I, J) PMC with stickiness at metaphase I. Scale bar $=10 \mu \mathrm{m}$. et al. 1998). Among which chromosomal aberrations are widely in use. Therefore, during the present study of $\mathrm{Zn}$ heavy metal toxicity analysis in S. cannabina, the method of chromosomal aberration analysis was used.

Zinc is an essential trace element for all living organisms and is a constituent of more than 200 metalloenzymes and other metabolic compounds. It assures the stability of biological molecules such as DNA and of biological structures such as membranes and ribosomes. Plants do not grow well in zinc-depleted soils however; it becomes toxic at concentrations higher than the limit. Heavy metal toxicity is an important factor governing the germination, survival, and growth of plants. As per the result of present investigation zinc metal toxicity significantly reduces the germination and survival percentages after a certain dose. Germination and establishment of seedlings are most vulnerable stages in the plant life cycle (Vange et al. 2004). Seedling growth is an important indicator of metal stress on the plant. The toxicity of some of the metals may be large enough that, seeds after germination, some growth become stunted and a stop growing. The reduction in seed germination and survival due to heavy metal stress is in conformity with the findings of other researchers (Morzek and Funicelli 1982, Iqbal and Mehmood 1991). Treatment of Leucaena leucocephala with $25,50,75$ and 100 ppm of lead and cadmium showed a gradual reduction in seed germination and seedling growth (Shafiq et al. 2008).

Study of microsporogenesis revealed various types of chromosomal aberration. Among the various types of induced chromosomal aberrations, the induction of bridges could be attributed to chromosome breaks, stickiness and breakage, and reunion of the broken ends. Chromosome bridges were somewhat damaged and the damage was reversible or irreversible depending on breakage and rejoining of chromosomes (Liu et al. 1996). Stickiness, Unorientation and Scattering at metaphase I may be due to the disturbance in spindle apparatus or due to suppression of spindle formation (Kumar and Rai 2007).

The appearance of lagging chromosome suggests spindle disturbances due to heavy metal toxicity. Gomez-Arroyo and Villibas-Pietrini (1983) described the lagging chromosome as "Chromosome with inactivated centromeres". Chromosomal bridges may be due to chro- 
mosomal stickiness (El-Khodary et al. 1990). Pagliarini (1990) reported that laggards may result from late chiasma terminalization. Similar results were obtained by Bipasha and Shella (1992) after using heavy metals.

It is obvious from the present experiment that heavy metal stress had a prominent effect on the phenotypic and genetic structure of $S$. cannabina. At the lowest dose of 25 and $50 \mathrm{ppm}$, germination percentages were not much affected by treatment doses. It can also be concluded that the level of these lower doses was within a tolerable limit. But at higher doses, it reduced dramatically and a similar trend was also observed in case of survival percentage. Conclusively, the present study indicated that $\mathrm{Zn}$ treatment was toxic to plants and may cause genetic damage in plants. The present study revealed that the upper limit of $\mathrm{Zn}$ tolerance in S. cannabina is $200 \mathrm{ppm}$. This indicates that $S$. cannabina may have a detoxification mechanism to cope with such a high concentration of heavy metals and this plant may be used to help reclamation of metal contaminated soil and it could serve as appropriate pioneer species to be used in short term remediation projects, to modify the harsh environment by providing additional organic matter and nutrients.

\section{Acknowledgements}

Authors are thankful to all the members of Plant Genetics Laboratory for their cooperation.

\section{References}

Bipasha, C. and Shella, S. 1992. Toxicity of some heavy metals in vivo and in vitro in Helianthus annuus. Mutat. Res. 283: 287-294.

Broadley, M. R., White, P. J., Hammond, J. P., Zelko, I. and Lu, A. 2007. Zinc in plants. New Phytol. 173: 677-702.

El-Khodary, S., Habib, A. and Haliem, A. 1990. Effect of herbicide tribunil on root mitosis of Allium cepa. Cytologia 55: 209-215.

Evans, D. O. and Rotar, P. P. 1987. Sesbania in Agriculture. Westview Press, Boulder.

Gomez-Arroyo, S. and Villabas-Pietrini, R. 1983. Chromosomal alterations induced by some chromium salts. Cytologia 48: 185-193.

Iqbal, M. Z. and Mehmood, T. 1991. Influence of cadmium toxicity on germination and growth of some common trees. Pak. J. Sci. Ind. Res. 34: 140-142.

Jain, R., Srivastava, S., Solomon, S., Shrivastava, A. K. and Chandra, A. 2010. Impact of excess zinc on growth parameters, cell division, nutrient accumulation, photosynthetic pigments and oxidative stress of sug garcane (Saccharum spp.). Acta Physiol. Plant. 32: 979-986.

Kiran, Y. and Sahin, A. 2006. The effect of cadmium on seed germination, root development and mitotic of root tip cells of lentil (Lens culinaris Medik). World J. Agr. Sci. 2: 196-200.

Kumar, G. and Rai, P. 2007. EMS Induced karyomorphological variations in maize (Zea mays L.). Inbreds. Turk. J. Biol. 31: 187-195.

Liu, C. Y., Fleskin-Nikitin, A., Li, S., Zeng, Y. and Lee, W. H. 1996. Inactivation of the mouse $B R C A 1$ gene leads to failure in the morphogenesis of the egg cylinder in early postimplantation development. Genes Dev. 10: 1835-1843.

Morzek, J. R. E. and Funicelli, N. A. 1982. Effect of zinc and lead on germination of Spartina alterniflora Loisel. seeds at various salinities. Environ. Exp. Bot. 22: 23-32.

Nag, P., Nag, P., Paul, A. K. and Mukherjee, S. 1984. Toxic action of zinc on growth and enzyme activities of rice seedlings. Environ. Pollut. 36: 45-59.

Pagliarini, M. S. 1990. Meiotic behaviour and pollen fertility in Aptenia cordifolia. Aizoaceae. Caryologia 43: 157-162.

Päivöke, A. E. A. 2003a. Soil pollution alters ATP and chlorophyll contents in Pisum sativum seedlings. Biol. Plant. 46: 145-148.

Päivöke, A. E. A. 2003b. Responses of Pisum sativum to soil arsenate, lead and zinc: A greenhouse study of mineral elements, phytase activity, ATP and chlorophylls. E-thesis, Univ. Helsinki, Helsinki.

Rank, J. and Nielsen, M. N. 1994. Evaluation of the allium anaphasetelophase test in relation to genotoxicity screening of industrial wastewater. Mutat. Res. 312: 17-24.

Salama, Z. A. and El Fouly, M. 2008. Evaluation of the efficiency of some Egyptian wheat Triticum aestivum L. cultivars to $\mathrm{Zn}$ deficiency through peroxidase activity and protein profile techniques. Not. Bot. Hort. Agrobot. 36: 42-46.

Shafiq, M., Iqbal, M. Z. and Athar, M. 2008. Effect of lead and cadmium on germination and seedling growth of Leucaena leucocephala. J. Appl. Sci. Environ. Manage. 12: 61-66.

Steinkellner, H., Mun-Sik, K., Helma, C., Ecker, S., Ma, T. H., Horak, O., Kundi, M. and Knasmüller, S. 1998. Genotoxic effects of heavy metals: comparative investigation with plant bioassays. Environ. Mol. Mutagen. 31: 183-191.

Vange, V., Hevchand, I. and Vandvik, V. 2004. Does seed mass and family affect germination and juvenile performance in Knautia arvensis? A study using failure time methods. Acta Oecol. 25: $169-178$. 